\title{
PENDAYAGUNAAN KETERAMPILAN MOTORIK PESERTA DIDIK SEKOLAH DASAR MELALUI PELATIHAN MEMBUAT BANGKU BELAJAR DARI BARANG BEKAS
}

\author{
Maria Purnama Nduru1 ${ }^{*}$, Siprianus See ${ }^{2}$, Berty Sadipun $^{3}$, Finsensius Mbabho", \\ Maria Finsensia Ansel 5 \\ 1,2,3,4,5 Universitas Flores, Ende, Indonesia \\ *Penulis Koresponsensi, email: mariapurnamand@gmail.com
}

\begin{abstract}
Motoric skills are one of the human potential in this case learners are very important to be developed and empowered at all times along with the growth of humans themselves. To develop motor skills that are beneficial for learners, there needs to be a simple activity that is adjusted to the age and cognitive level of learners. Training to make benches learn from used goods to learners, actually aims to use motor skills and direct learners to do simple activities but have a very positive impact on the growth and development of learners themselves. This method of activity is a training that has several simple stages, ranging from providing explanations about the benefits of used goods and motor skills, learners are formed in groups in an organized manner, prepare materials and tools, then carry out tasks by utilizing tools and materials in making study benches. The result of this training activity is in the form of objects that are useful or have useful value, namely a simple learning bench in accordance with the creativity of learners and the achievement of the utilization of motor skills in a more useful direction for the learners themselves. Thus it can be concluded that the activities of this training can create enthusiasm in using the motor skills of learners early on, so that it can be one of the provisions for their survival.
\end{abstract}

Keywords: Motoric Skills, Training, used goods

\begin{abstract}
Abstrak. Keterampilan motorik merupakan salah satu potensi manusia dalam hal ini peserta didik yang amat penting untuk dikembangkan dan diberdayakan setiap saat seiring dengan pertumbuhan manusia itu sendiri. Untuk mengembangkan keterampilan motorik yang bermanfaat bagi peserta didik maka perlu adanya suatu aktivitas sederhana yang disesuaikan dengan umur dan tingkat kognitif peserta didik. Pelatihan membuat bangku belajar dari barang bekas kepada peserta didik, sesungguhnya bertujuan untuk mendayagunakan keterampilan motorik dan mengarahkan peserta didik untuk melakukan aktivitas sederhana namun memiliki dampak yang amat positif terhadap tumbuh kembangnya peserta didik itu sendiri. Metode kegiatan ini adalah pelatihan yang memiliki beberapa tahap sederhana, mulai dari memberikan penjelasan tentang manfaat barang bekas dan keterampilam motorik, peserta didik dibentuk berkelompok secara terorganisir, menyiapkan bahan dan alat, kemudian melaksanakan tugas dengan memanfaatkan alat dan bahan dalam membuat bangku belajar. Hasil kegiatan dari pelatihan ini adalah berupa benda yang bermanfaat atau memiliki nilai guna yaitu bangku belajar yang sederhana sesuai dengan kreativitas peserta didik dan tercapainya pendayagunaan keterampilan motorik ke arah yang lebih bermanfaat bagi peserta didik itu sendiri. Dengan demikian dapat disimpulkan bahwa kegiatan dari pelatihan ini dapat menciptakan semangat dalam mendayagunakan keterampilan motorik peserta didik sejak dini, sehingga dapat menjadi salah satu bekal untuk kelangsungan hidupnya.
\end{abstract}

Kata Kunci: Keterampilan Motorik, Pelatihan, barang bekas

How to Cite: Nduru, M.P., See, S., Sadipun, B., Mbabho, F., \& Ansel, M.F. (2021). Pendayagunaan Keterampilan Motorik Peserta Didik Sekolah Dasar Melalui Pelatihan Membuat Bangku Belajar dari Barang Bekas. Mitra Mahajana: Jurnal Pengabdian Masyarakat, 2(3), 220-225. https://doi.org/10.37478/mahajana.v2i3.888

\section{PENDAHULUAN}

Kegiatan ini dilatarbelakangi atas dasar keprihatinan kepada peserta didik pada era ini, yang lebih suka bermain gadget dari pada melakukan aktivitas yang memanfaatkan potensi dirinya dengan dukungan otak dan fisik. Peserta didik pada sejak dini tentu tidak diharapkan menjadi manusia malas yang hanya bergantung pada teknologi elektronik yang dari waktu ke waktu dapat menjadi remote bagi otak dan fisiknya. Sebagai aktivis pada bidang pendidikan maka merasa perlu tim dosen PGSD untuk meransang motorik peserta didik dengan suatu aktivitas sederhana yaitu membuat bangku belajar dari bahan bekas yang mudah diperoleh dari sekitar lingkungan tempat peserta didik tinggal. Kegiatan ini sekaligus 
sebagai bentuk pelaksanaan Tri Dharma Perguruan Tinggi yaitu pada aspek pengabdian kepada masyarakat.

Kegiatan Pelatihan Peningkatan Motorik melalui membuat bangku belajar kepada Para pesertta didik di SDI Onekore 5 kecamatan Ende Tengah, sesungguhnya memiliki tujuan mendayagunakan kemampuan motorik peserta didik agar memanfaatkan otak dan fisik secara lebih efektif dan efisien dan sekaligus menyadarkan kepada peserta didik bahwa barang bekas yang tidak dipakai lagi dapat dimanfaatkan dan merubahnya menjadi sesuatu yang bermanfaat. Siti Maghfirah (2019) dalam hasil penelitiannya menjelaskan bahwa dengan diterapkannya langkah- langkah melalui pemanfaatan media barang bekas dalam meningkatkan perkembangan motorik halus anak di Tk Wiyata Mandala Langsa mendapatkan respon positif dari peserta didik dan telah menunjukkan hasil yang optimal. Perkembangan motorik halus anak di tandai dengan meningkatnya pemahaman anak dalam mengerjakan setiap langkah-langkah dari kegiatan menyusun bentuk bunga dari tutup botol bekas. Selain itu Walsimah dkk (2020) pada hasil penelitiannya menyimpulkan bahwa penggunaan media bahan bekas dapat meningkatkan 52,17\% motorik halus anak pada TK Tunas Baru Desa Kusau Makmur Kecamatan Tapung Hulu.

Menurut Purwanto (1986) keterampilan berasal dari kata terampil yang artinya mahir, sedangkan motorik itu berkaitan dengan kemampuan memanfaatkan potensi anggota tumbuh yang salah satunya adalah tangan manusia secara lebih efektif dan efisien. Dengan demikian keterampilan motorik adalah suatu aktivitas yang menggerakan anggota tubuh dalam hal ini adalah tangan manusia untuk tujuan atau menghasilkan sesusatu bermanfaat bagi manusia itu sendiri. Sedangkan menurut Rosdianawati (2003) kegiatan daur ulang atau memanfaatkan barang bekas adalah membuat mainan atau benda dengan mempergunakan barang-barang bekas, yang tidak terpakai seperti kotak korek api, botol-botol plastik, karton, kayu, dll. Dengan demikian kegiatan mendaur ulang dengan cara membuat botol plastik menjadi bangku belajar adalah suatu aktivitas yang menggunakan tangan sebagai alat penggerak utama dan bekerjasama dengan anggota tubuh lainnya yang dikendalikan oleh otak sebagai manifestasi dari keterampilan motorik.

Keterampilan motorik berkaitan dengan pengendalian gerakan jasmaniah melalui kegiatan pusat syaraf, urat syaraf, dan otot yang terorganisasi (Hurlock, 2007). Keterampilan motorik memberikan banyak manfaat bagi kehidupan anak, antara lain menjaga kesehatan anak, katarsis emosional, kemandirian, hiburan diri, sosialisasi dan membentuk konsep diri yang positif. Keterampilan motorik perlu dilatih agar terampil dan membawa manfaat bagi anak. Dewasa ini banyak barang yang ditemukan dalam kemasan plastik, khususnya minuman. Oleh karena itu banyak dijumpai sampah plastik seperti tas plastik, dan botol plastik minuman bekas di lingkungan sekitar. Sampah plastik membutuhkan waktu yang lama untuk terurai. Menurut NOAA (National Oceanic And Atmospheric) tas plastik membutuhkan waktu 10-20 tahun untuk terurai dan sebuah botol plastik membutuhkan waktu 450 tahun untuk terurai (Avisena, 2018). Dengan demikian salah satu bentuk melatih dan meningkatan keterampilan motorik anak dalam hal ini peserta didik dapat melalui suatu aktivitas pemanfaatkan botol plastik menjadi sesuatu barang yang nilai kegunaannya lebih tinggi. Selain itu aktivitas pemanfaatan berang bekas ini juga sebagai bentuk partisipasi peserta didik dalam memelihara bumi.

\section{METODE PELAKSANAAN}

Metode kegiatan ini adalah berupa pelatihan yang memiliki beberapa tahap; 1 . menjelasan mengenai manfaat barang bekas dan keterampilan motorik oleh tim; pada tahap ini siswa diberikan pemahaman tentang apa itu barang bekas dan bagaimana manfaatkannya serta bagaimana mendayagunakan keterampilan motoriknya secara efektif, 2) membagi peserta didik dalam bentuk kelompok; pada tahap ini siswa dibagi ke dalam 5 kelompok, setiap kelompok terdiri dari 5 siswa yang diberikan tugas dan tanggung jawab yang sama untuk saling bekerjasama, 3)menyiapkan bahan dan alat: pada tahap ini siswa pada setiap kelompok 
diarahkan untuk menyiapkan semua bahan dan alat yang dibutuhkan. Adapun bahan atau barang bekas yang dimanfaatkan dalam pelatihan ini adalah botol plastik air mineral berukuran sedang, besar, dos bekas minuman mineral, busa spon, ferlak kain penutup spon, sampah kertas/plastik, isolasi bening dan alat berupa gunting dan pisau karter. 4) menjelaskan cara membuat bangku belajar; pada tahap ini siswa diberikan pengetahuan tentang langkah-langkah bagaimana cara membuat bangku dari bahan bekas yang praktekan secara langsung oleh tim untuk diamati secara fokus oleh peserta didik, 5) setiap kelompok mulai diarahkan untuk memanfaatkan bahan dan alat sesuai dengan langkah-langkah cara membuat bangku; tahap ini peserta pada kelompok masing-masing mulai bekerjasama membuat bangku belajar dengan memanfaatkan bahan dan alat yang ada.

\section{HASIL DAN PEMBAHASAN}

Kegiatan ini diawali dengan penjelasan dan contoh dari tim kepada peserta didik tentang pentingnya pemanfaatan barang bekas dan menjadikannya sesuatu yang berguna dalam mengoptimalkan aktivitas motorik dari peserta didik, seperti yang tergambar pada gambar berikut ini:

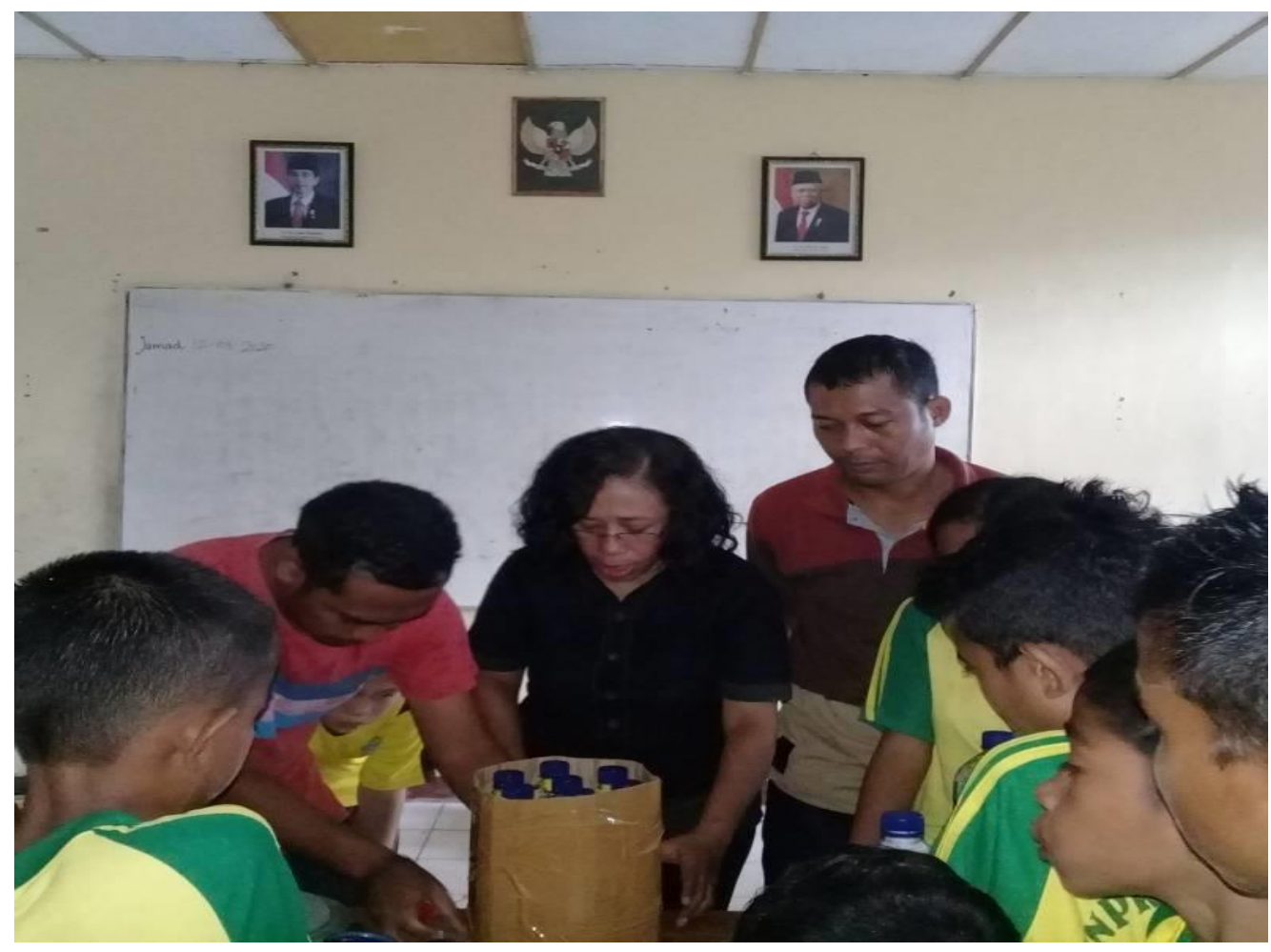

Gambar 1. Peserta didik mendengar dan melihat cara membungkus botol plastik

Pada tahap ini peserta didik tentu perlu memahami tentang cara membuat bangku belajar dari barang bekas dan apa saja aktivitas tubuh yang dapat memberdayakan keterampilan motoriknya. Tim menjelaskan secara rinci dengan cara mendemonstrasi secara langsung tahapan dan cara merangkai bahan-bahan bekas yang telah disediakan yang kemudian dihubungkan dengan keterampilan motorik.

Setelah mendengarkan penjelasan dan contoh dari wujud keterampilan motorik melalui pemanfaatan barang bekas, peserta didik mulai membentuk kelompok dan melakukan aktivitas merangkai botol plastik seperti yang tergambar pada gambar berikut ini: 


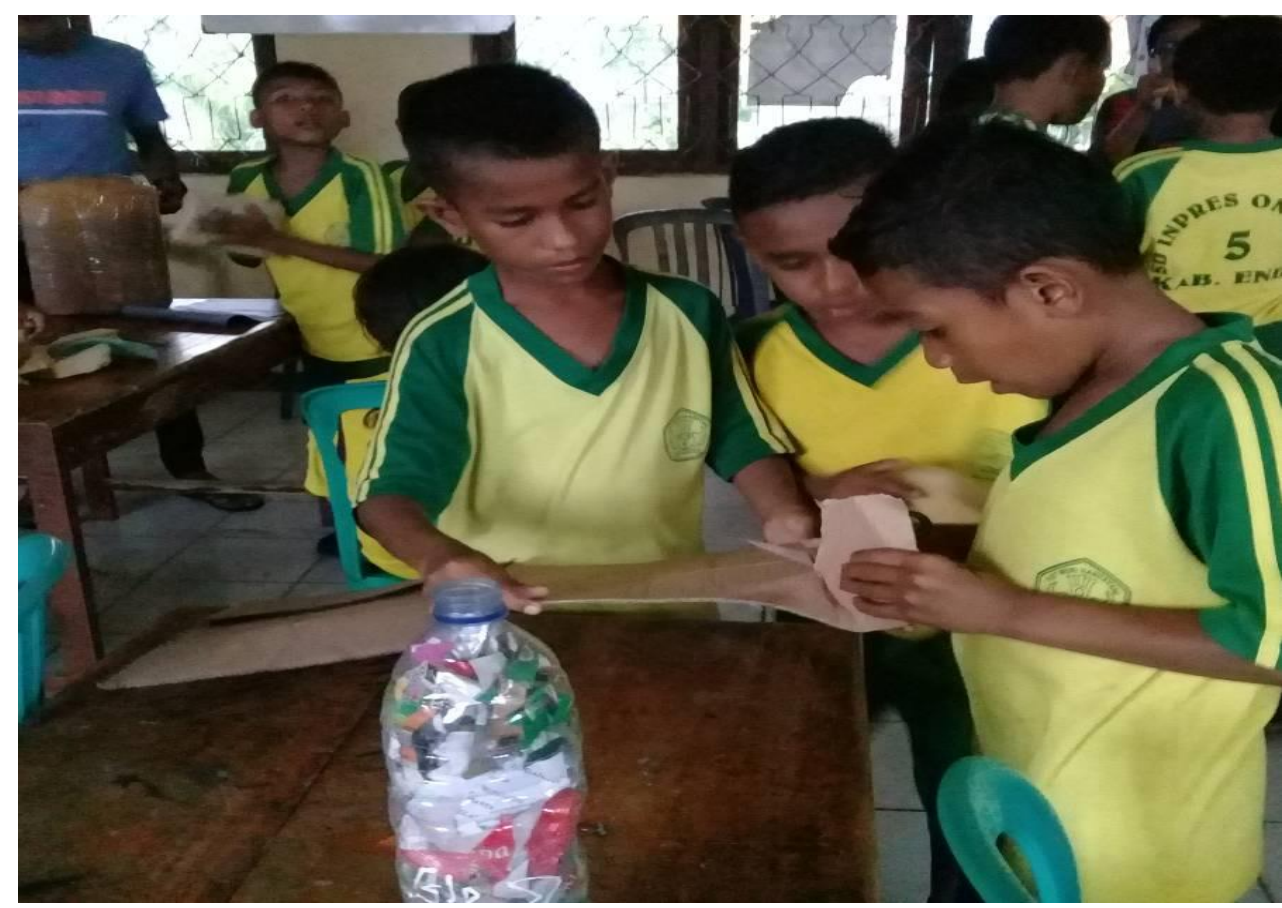

Gambar 2. Aktivitas peserta didik Membuat Bangku belajar dari botol plastik bekas

Pada tahap ini setiap siswa dalam kelompok mulai memanfaatkan keterampilan motoriknya dengan melakukan aktivitas membuat bangku belajar dari barang bekas dengan bahan-bahan seperti; botol plastik, spon bekas, ferlak spon, kertas permen, karet plastik, isolasi bening, benang, plastik dan alat; seperti pisao karter, gunting, jarum dll. Pada tahap ini juga peserta didik mulai untuk aktif menunjukan kreatifitasnya dalam merangkai dan menyusun botol serta membuatnya lebih menarik. Kegiatan ini dimulai dari siswa mengambil beberapa botol kemasan air minum berukuruan sedang atau besar (jumlah botol disesuaikan dengan berapa lebar bangku yang dinginkan), dalam demonstrasi ini menggunakan 7 botol ukuran sedang. Setiap botol diisi dengan sampah kertas, plastik kemasan makanan atau miniman ringan yang telah digunting berukuran kecil sampai penuh, setelah itu botol-botol plastik tersebut dililit dengan lembaran dos bekas yang ukurannya sesuai dengan lebar dan tinggi botol dibantu dengan isolasi bening yang dililit pula pada lingkaran dos tersebut agar lebih kuat menempel pada botol plastik, kemudian pada bagian atas lingkaran botol-botol yang telah dililit dengan dos dan isolasi diletakan busa spon bekas sesuai dengan ukuran atau lebar bangku, dan diakhir tahapan ini bangku setengah jadi tersebut kemudian dibungkus dengan ferlak sova dengan warna yang menarik sesuai dengan selera dan kemudian dijahit dengan rapih menggunakan jarum jahit dan benang plastik.

Kegiatan ini membutuhkan kerjasama anggota kelompok secara aktif, sehingga proses pembuatan bangku belajar dari barang bekas dapat mencapai apa yang dinginkan. Berdasarkan pengamatan tim, peserta didik secara berkelompok sangat aktif dan saling membantu satu sama lain, mulai dari menyiapkan bahan dan alat sampai pada tahap memanfaatkan alat dan bahan yang ada dengan penuh kreatifitas. Ini artinya peserta didik secara tidak langsung telah menunjukan keterampilan motoriknya yang terwujud dari adanya atkivitas tersebut.

Selain itu pada tahap ouput kegitan ini, peserta didik menunjukan dan menjelaskan hasil yang telah dikerjakannya, seperti yang tergambar pada gambar berikut ini: 


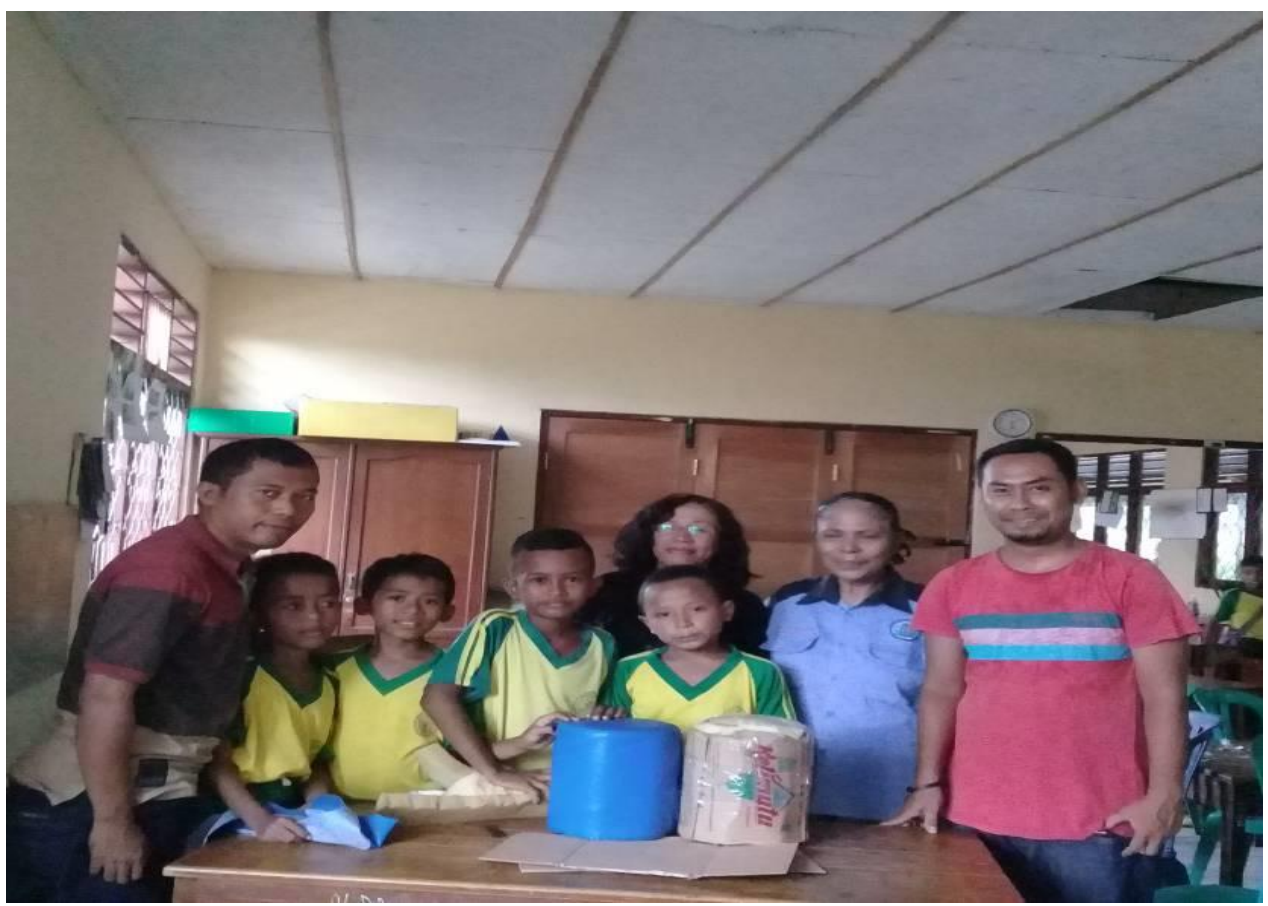

Gambar 3. Peserta didik menunjukan hasil dari aktivitas membuat bangku belajar.

Hasil atau ouput dari kegiatan ini sesungguhnya bukan hanya pada hasil bangku belajar yang sederhana, nyaman, dan menarik dari peserta didik, namun yang paling penting adalah pada aktivitas mendayagunakan keterampilan motoriknya. Dengan adanya aktivitas ini peserta didik akan kurang bergantung pada teknologi yang dapat memperlemah fungsi anggota tubuh salah satunya adalah tangan. Ketertarikan pada aktivitas memanfaatkan barang bekas dapat meningkatkan kreativitas dan inovasi dari peserta didik. Kemampuan kognitif peserta didik juga terus mengalami peningkatan. Fokus dan tekun menjadi kebiasaan yang tentu akan dimiliki oleh peserta didik secara langsung sebagai dampak positif dari kegiatan tersebut. Oleh sebab itu secara keseluruhan kegiatan pelatihan ini sesunggahnya berhasil merangsang dan mengoptimalkan keterampilan motorik dari peserta didik.

\section{SIMPULAN DAN TINDAK LANJUT}

Berdasarkan hasil dan pembahasan dari kegiatan pelatihan membuat bangku belajar dari barang bekas dapat penulis simpulkan bahwa:

1. Pelatihan ini dapat menghasilkan karya berupa bangku belajar sebagai bentuk dari kreativitas peserta didik.

2. Pelatihan ini dapat secara optimal mendayagunakan keterampilan motorik dari peserta didik.

3. Pelatihan ini dapat menjadi referensi yang memotivasi peserta didik untuk melakukan aktivitas-aktivitas sederhana namun bermanfaat dengan memanfaatkan sumber daya yang ada di lingkungan tempat mereka tinggal.

\section{DAFTAR PUSTAKA}

Avisena, A. (2018). Mengapa Plastik Membutuhkan Waktu yang lama untuk bisa terurai. bobo.grid.id

Hurlock, E.B. (2007). Perkembangan Anak. Jakarta: Erlangga

Purwanto, N. (1986). Ilmu Pendidikan Teoretis dan Praktikum. Bandung: Remaja Rosdakarya

Suminto, S. (2017). Ecobrick: solusi cerdas dan kreatif untuk mengatasi sampah plastik. Productum: Jurnal Desain Produk (Pengetahuan dan Perancangan Produk), 3(1), 
26-34. https://doi.org/10.24821/productum.v3i1.1735

Rosdianawati, R. (2003). Kreasi Daur Ulang Barang Bekas. Bandung: Remaja Rosdakarya. https://doi.org/10.32505/atfaluna.v2i1.938

Waslimah, E., Alim, M. L., \& Syahrial, S. (2020). Peningkatan Kemampuan Motorik Halus Anak dengan Metode Demonstrasi dalam Pemanfaatan Bahan Bekas. Journal of Education Research, 1(3), 265-275. https://doi.org/10.37985/jer.v1i3.31 